\title{
EFEKTIVITAS DAN TINGKAT PARTISIPASI MASYARAKAT TERHADAP PROGRAM PENGENTASAN KEMISKINAN PERKOTAAN (P2KP) DI KOTA BANDAR LAMPUNG
}

\author{
(EFFECTIVENESS AND PARTICIPATION SOCIETY AGAINST THE \\ URBAN POVERTY ERADICATION PROGRAM (P2KP) IN BANDAR \\ LAMPUNG)
}

Helvi Yanfika

Jurusan Sosial Ekonomi Pertanian

Fakultas Pertanian Universitas Lampung

\begin{abstract}
The goal of provision of venture capital through P2KP is to improve the economy and provide infrastructure assistance to the urban poor in the form of concern that the government is "facilitating" the passage "public participation process". Purposes of this study are to determine the level of effectiveness, know the dynamics of group relationships, determine the relationship of program characteristics of community participation in the program, and determine the relationship at the level of stakeholder support for urban poverty eradication program $(\mathrm{P} 2 \mathrm{KP})$ in the city of Bandar Lampung. The research was conducted in the city of Bandar Lampung in July-October 2011. The sample in this study were drawn using simple random technique (simple random sampling), and the respondent sample was taken from the population of members of SelfHelp Groups (SHGs) of poor city of Bandar Lampung group, in order to obtain a sample of 39 respondents. Data analyses in this study were tabulation and descriptive method. To test the hypothesis, non-parametric statistical test Spearman Rank correlation was used. The study results show that in general urban poverty eradication program (P2KP) in Bandar Lampung is in fairly good views. Assessment of the dynamics of the group (X1) is quite good most of the respondents are $53.85 \%$ in the medium category, and program characteristics (X2) was $71.79 \%$ which is good enough, as well as the support of stakeholders (X3) is 58.97\%, and public participation (Y1) in the high category is $71.79 \%$, indicating the effectiveness of programs in the city of Bandar Lampung P2KP pretty good, and the results of the analysis showed a significant relationship between the dynamics of the group, the characteristics of program with the participation of stakeholders support to the program in the city of Bandar Lampung P2KP with 99\% confidence level.
\end{abstract}

Keywords: Effectiveness, Participation, Poverty Eradication 


\section{PENDAHULUAN}

Kemiskinan di Indonesia dapat dilihat dari tiga pendekatan yaitu kemiskinan alamiah, kemiskinan struktural, dan kesenjangan antar wilayah. Persoalan pengangguran lebih dipicu oleh rendahnya kesempatan dan peluang kerja bagi angkatan kerja di pedesaan. Upaya untuk menanggulanginya harus menggunakan pendekatan multidisiplin yang berdimensi pemberdayaan. Pemberdayaan yang tepat harus memadukan aspek-aspek penyadaran, peningkatan kapasitas, dan pendayagunaan.

Kelompok masyarakat kota dicirikan dengan masyarakat yang sudah meninggalkan tradisi dan adat-istiadat. Di sisi lain masyarakat miskin kota belum memiliki mobilitas yang tinggi dan masih terbatas akses terhadap berbagai kemajuan industrialisasi, informasi dan tehnologi. Seiring dengan kondisi ini perubahan yang terjadi pada masyarakat kota berlangsung secara cepat bila dibandingkan dengan komunitas masyarakat desa. Peran dari stakeholder termasuk pemimpin kelompok yang ada dalam masyarakat kota menjadi sangat penting untuk diperhatikan oleh semua pihak maupun agen pembaharu dalam pemberdayaan kelompok swadaya masyarakat miskin kota.

Partisipasi masyarakat untuk mengentaskan kemiskinan perkotaan dapat diatasi melalui berbagai program baik melalui pemerintah, swasta maupun LSM. Salah satu program yang sedang berjalan yaitu program P2KP dimana partisipasi secara kelompok lebih ditonjolkan untuk mengembangkan usahausaha ekonomi produktif. Kelompok keswadayaan masyarakat merupakan kelembagaan yang dirancang untuk membangun kembali kehidupan masyarakat mandiri yang mampu mengatasi kemiskinannya sendiri. Di samping itu kelompok keswadayaan masyarakat mengemban misi untuk menumbuhkan kembali ikatan-ikatan sosial dan menggalang solidaritas sosial sesama warga agar saling bekerja sama demi kebaikan bersama.

Pemberian modal usaha melalui program P2KP guna meningkatkan ekonomi serta memberi bantuan sarana dan prasarana kepada masyarakat miskin di perkotaan adalah dalam bentuk kepedulian pemerintah yang bersifat "memfasilitasi" berjalannya "proses partisipasi masyarakat". Permasalahannya adalah sejauh mana tingkat efektivitas program pengentasan kemiskinan perkotaan (P2KP); Bagaimana hubungan tingkat dinamika kelompok dan karakteristik program terhadap partisipasi masyarakat pada program pengentasan kemiskinan perkotaan (P2KP); serta Sejauh mana hubungan tingkat dukungan stakeholder pada program pengentasan kemiskinan perkotaan (P2KP) di Kota Bandar Lampung.

\section{METODE PENELITIAN}

Data yang digunakan dalam penelitian ini meliputi data primer dan data sekunder. Metode yang digunakan dalam penelitian ini adalah metode survey, yaitu penelitian yang mengambil sampel dari satu populasi dan menggunakan angket atau kuisioner sebagai alat pengumpulan data yang pokok. Populasi 
penelitian ini adalah Kelompok Swadaya Masyarakat (KSM) pelaksana Program Penanggulangan Kemiskinan Perkotaan (P2KP) Kota Bandar Lampung. Sampel penelitian dan teknik pengambilan sampel dilakukan dengan acak (random).

$$
\mathrm{n}=\frac{N}{N(d i)^{2}+1}
$$

dimana $\mathrm{n}$ adalah jumlah sampel, $\mathrm{N}$ adalah jumlah populasi, di adalah nilai presisi (ketelitian) sebesar $95 \%$

Pengolahan data menggunakan metode tabulasi dan kuantitatif. Analisis data dilakukan secara deskriptif dan uji statistik non parametrik. Uji statistik yang digunakan adalah Uji Korelasi Rank Sperman untuk mengetahui keeratan hubungan antar variable (Siegel, 1997).

$$
r_{s}=1-\frac{6 \sum_{i=1}^{n} d i^{2}}{n^{3}-n}
$$

dimana rs adalah Koefisien korelasi, di adalah Selisih jenjang antara kedua perubah yang diuji, dan $\mathrm{N}$ adalah Jumlah sampel

\section{HASIL DAN PEMBAHASAN}

\section{Variabel Tingkat Dinamik Kelompok (X1)}

Berdasarkan hasil penelitian, tingkat dinamika kelompok (X1) berkisar antara skor 119-145 dengan rata-rata skor dinamika kelompok 134,33. Adapun hasil skor 119-128 termasuk kategori rendah dengan jumlah 7 orang, dan skor 128,01-137 termasuk kategori sedang dengan jumlah 21 orang, dan skor kategori tinggi 137,01- 145 dengan jumlah 11 orang. Apabila ditinjau dari tingkat dinamika kelompok termasuk dalam kategori sedang, hal ini menunjukkan tingkat dinamika kelompok dalam partisipasi kegiatan program P2KP cukup baik. Sebaran responden menurut tingkat dinamika kelompok dapat dilihat pada Tabel 1.

Tabel 1. Keadaan variabel tingkat dinamika kelompok

\begin{tabular}{clcc}
\hline $\begin{array}{c}\text { Tingkat Dinamika } \\
\text { kelompok }\end{array}$ & Kategori & Jumlah (orang) & Persentase (\%) \\
\hline $119,00-128,00$ & Rendah & 7 & 17,95 \\
$128,01-137,00$ & Sedang & 21 & 53,85 \\
$137,01-145,00$ & Tinggi & 11 & 28,20 \\
\hline Jumlah & & 39 & $100 \%$ \\
\hline
\end{tabular}

Keterangan: tingkat dinamika kelompok skor rata-rata: 134,33 (kategori sedang)

Tingkat dinamika kelompok diukur dari beberapa indikator yaitu, tujuan kelompok, struktur kelompok, fungsi dan tugas, pemeliharaan kelompok, 
kekompakan kelompok, iklim kelompok, tekanan pada kelompok, efektifitas kelompok, serta agenda terselubung.

\section{Variabel Karakteristik Program (X2)}

Berdasarkan hasil penelitian tingkat karakteristik program (X2) berkisar antara skor 50,00-70,00 dengan rata-rata skor 59,69. Adapun hasil skor 50,0056,00 termasuk kategori rendah dengan jumlah 6 orang, dan skor 56,01-63,00 termasuk kategori sedang dengan jumlah 28 orang, dan skor kategori tinggi 63,01-70,00 dengan jumlah 5 orang. Sebaran responden tingkat karakteristik program dapat dilihat pada Tabel 2.

Tabel 2. Tingkat karakteristik program

\begin{tabular}{clcc}
\hline $\begin{array}{c}\text { Karakteristik } \\
\text { Program }\end{array}$ & Kategori & $\begin{array}{c}\text { Jumlah } \\
\text { (orang) }\end{array}$ & Persentase (\%) \\
\hline $50,00-56,00$ & Rendah & 6 & 15,38 \\
$56,01-63,00$ & Sedang & 28 & 71,79 \\
$63,01-70,00$ & Tinggi & 5 & 12,82 \\
\hline Jumlah & & 39 & 100,00 \\
\hline
\end{tabular}

\section{Dukungan Stakeholder (X3)}

Berdasarkan hasil penelitian tingkat dukungan stakeholders (X3) berkisar antara skor 85,00-108,00 dengan rata-rata skor 97,95. Adapun hasil skor 85,0093,00 termasuk kategori rendah dengan jumlah 2 orang, dan skor 93,01-101,00 termasuk kategori sedang dengan jumlah 23 orang, dan skor kategori tinggi 101,01-108,00 dengan jumlah 14 orang. Sebaran responden tingkat dukungan stakeholders dapat dilihat pada Tabel 3.

Tabel 3. Dukungan Stakeholders

\begin{tabular}{cccc}
\hline Dukungan & Kategori & Jumlah (orang) & Persentase (\%) \\
Stakeholders & Rendah & 2 & 5,13 \\
$85,00-93,00$ & Sedang & 23 & 58,97 \\
$93,01-101$ & Tinggi & 14 & 35,97 \\
$101,01-108$ & & 39 & 100,00 \\
\hline Jumlah & & 39 \\
\hline
\end{tabular}

Keterangan: tingkat peranan pemimpin skor rata-rata: 53,10 (kategori sedang)

\section{Tingkat Partisipasi Masyarakat Terhadap Program P2KP (Y)}

Berdasarkan hasil penelitian tingkat partisipasi $(\mathrm{Y})$ berkisar antara skor $60,00-80,00$ dengan rata-rata skor 75,74. Adapun hasil skor 60,00-67,00 termasuk kategori rendah dengan jumlah 3 orang, dan skor 67,01-74,00 termasuk kategori sedang dengan jumlah 8 orang, dan skor kategori tinggi 74,01-80,00 dengan jumlah 28 orang (Tabel 4). 
Tabel 4. Tingkat partisipasi masyarakat terhadap program P2KP

\begin{tabular}{cccc}
\hline Tingkat Partisipasi & Kategori & Jumlah (orang) & Persentase (\%) \\
\hline $60,00-67,00$ & Rendah & 3 & 7,69 \\
$67,01-74,00$ & Sedang & 8 & 20,51 \\
$74,01-80,00$ & Tinggi & 28 & 71,79 \\
\hline Jumlah & & 39 & 100,00 \\
\hline
\end{tabular}

Keterangan: tingkat partisipasi terhadap program P2KP rata-rata: 75,74 (kategori tinggi)

\section{Faktor-faktor yang berhubungan dengan tingkat partisipasi masyarakat terhadap program P2KP}

Hubungan antara variabel-variabel $\mathrm{X}$ (dinamika kelompok, kesesuain program, dan dukungan stakeholders) dengan variabel Y (persepsi) dianalisis dengan menggunakan uji korelasi peringkat Rank Spearman. Untuk mengetahui secara langsung hubungan antara variabel $X$ dan variabel $Y$ dapat dilihat pada Tabel 5.

Tabel 5. Hasil perhitungan korelasi peringkat Rank Spearman oleh harga rs pada tiap hubungan variabel $X$ dan variabel $Y$

\begin{tabular}{clccc}
\hline \multirow{2}{*}{ No. } & \multirow{2}{*}{ Variabel Bebas } & \multirow{2}{*}{ rs hitung } & \multicolumn{2}{c}{$\mathrm{t}$ table } \\
\cline { 4 - 5 } & & & $\mathrm{a}=0,05$ & $\mathrm{a}=0,01$ \\
\hline 1 & Dinamika Kelompok & 0,462 & nyata & Nyata \\
2 & Karaktersitik Program & 0,427 & nyata & nyata \\
3 & Dukungan stakeholders & 0,503 & nyata & nyata \\
\hline
\end{tabular}

Tabel 5 menunjukan bahwa variabel-variabel yang mempunyai nilai $\mathrm{t}$ hitung lebih besar pada nilai $t$ tabel pada $\alpha=0,05$ dan $\alpha=0,01$ atau yang berhubungan nyata adalah dinamika kelompok, kesesuaian program, dan dukungan stakeholders dengan tingkat kepercayaan $99 \%$.

\section{Implikasi Temuan}

Elemen pendukung partisipasi kelompok dipengaruhi oleh karakteristik program. Oleh karenanya perlu kejelasan yang lebih detail dari program tersebut dan diikuti dengan sosialisasi dengan melibatan masyarakat dalam pelaksanaannya sehingga mereka benar-benar merasa merupakan bagian dari kegiatan tersebut. Dengan keterlibatan masyarakat dalam program ini akan mampu meningkatkan partisipasi masyarakat secara langsung karena berdasarkan pengalaman apabila suatu program jelas dan lebih transparan kegiatannya baik perencanaannya, pelaksanaannya, maka secara signifikan akan mempengaruhi tingkat partisipasi masyarakat. Oleh karenanya dalam karakteristik perlu peningkatkan sub variabel kejelasan program dan kesesuaian 
jadwal karena secara langsung mempengaruhi tingkat partisipasi kelompok dalam implementasi program pengentasan kemiskinan perkotaan.

Karakteristik dari suatu program akan mempengaruhi secara signifikan terhadap dukungan dari berbagai stakeholders yang ikut berpartisipasi untuk mensukseskan program pengentasan kemiskinan khususnya di perkotaan. Peran stakeholders dalam desain program, perencanaan program didasarkan pada profil program secara jelas dan teliti sehingga mereka dalam membantu mengentaskan kemiskinan mencapai sasaran yang tepat. Untuk mengoptimalkan partisipasi kelompok tidak terlepas dari dukungan stakeholders.

Kemandirian kelompok dipengaruhi langsung oleh partisipasi kelompok. Kelompok lebih besar pengaruhnya dibandingkan karakteristik program dan dukungan stakeholders terhadap kemandirian kelompok. Oleh karenanya untuk meningkatkan kemandirian kelompok harus diikuti dengan peningkatan partisipasi kelompok. Untuk meningkatkan kemandirian kelompok dalam program pengentasan kemiskinan perkotaan dapat dilakukan dengan peningkatan karakteristik program dan partisipasi kelompok, karena optimalisasi terhadap kedua variabel tersebut akan berdampak pada semakin cepatnya kemandirian kelompok swadaya masyarakat.

\section{SIMPULAN DAN SARAN}

\section{Simpulan}

Hasil kajian menunjukkan bahwa secara umum program pengentasan kemiskinan di perkotaan (P2KP) tergolong cukup baik dilihat dari rata-rata penilaian responden berada pada kategori sedang. Penilaian terhadap dinamika kelompok $\left(X_{1}\right)$ sebagian besar responden cukup baik yaitu 53,85\% pada kategori sedang, dan karakteristik program $\left(\mathrm{X}_{2}\right)$ pun cukup baik yaitu $71,79 \%$ berada pada kategori sedang, serta dukungan stakeholders $\left(X_{3}\right)$ berada pada kategori sedang yakni 58,97\%, dan partisipasi masyarakat $\left(\mathrm{Y}_{1}\right)$ pada kategori tinggi yaitu 71,79 \%. Hal ini menunjukkan efektivitas program P2KP di kota Bandar Lampung cukup baik.

Analisis hubungan antar variabel tingkat dinamika kelompok dengan partisipasi masyarakat terhadap program P2KP menunjukkan hasil yang signifikan dengan tingkat kepercayaan 99\%, hal ini menunjukkan bahwa terdapat hubungan antara tingkat dinamika kelompok (x1) dengan partisipasi $(\mathrm{Y})$.

Analisis hubungan antar variabel tingkat karakteristik program dengan partisipasi masyarakat terhadap program P2KP menunjukkan hasil yang signifikan dengan tingkat kepercayaan 99\%, hal ini menunjukkan bahwa terdapat hubungan antara tingkat karakteristik program $(\mathrm{x} 2)$ dengan partisipasi $(\mathrm{Y})$. 
Analisis hubungan antar variabel tingkat dukungan stakeholders dengan partisipasi masyarakat terhadap program P2KP menunjukkan hasil yang signifikan dengan tingkat kepercayaan 99\%, hal ini menunjukkan bahwa terdapat hubungan antara tingkat dukungan stakeholders (x3) dengan partisipasi (Y).

\section{Saran}

Perlu pengembangan penelitian sejenis, yaitu penelitian dengan variabel yang lebih luas dan mendalam mengingat dari penelitian ini ditemukan pengaruh variabel lain yang tidak dapat dijelaskan dalam penelitian ini yang mempengaruhi partisipasi kelompok maupun kemandirian kelompok swadaya masyarakat.

Perlu kegiatan yang dapat meningkatkan partisipasi kelompok melalui peningkatan dinamika kelompok, karakteristik program dan dukungan stakeholders, karena dengan peningkatan kedinamisan suatu kelompok juga diikuti dengan pemberian pemahaman atau sosialisasi tentang suatu program secara jelas dan transparan kepada semua pihak yang terlibat dalam melaksanakan program tersebut, sehingga kegiatan yang akan dicapai sesuai dan tepat pada sasaran yang membutuhkan.

Perlu dukungan dari pemerintah dan pihak-pihak terkait lainnya seperti akademisi atau Perguruan Tinggi, LSM dan swasta lainnya untuk meningkatkan program pemberdayaan masyarakat. Mengingat P2KP ini merupakan bagian dari program pemberdayaan masyarakat yang manfaatnya sangat besar bagi masyarakat khususnya masyarakat miskin, sehingga diharapkan dukungan yang lebih luas dari pemerintah daerah sehingga wilayah yang belum pernah mendapatkan kesempatan program sejenis ini juga akan ikut mendapat kesempatan program pemberdayaan.

\section{DAFTAR PUSTAKA}

Siegel, S. 1997. Statistik Non-parametrik Untuk Ilmu-ilmu Sosial. Diterjemahkan oleh Z. Suyuti dan L. Simatupang. Gramedia. Jakarta. 374 halaman. 